\title{
Effects of inter-varietal diversity, biotic stresses and environmental productivity on grain yield of spring barley variety mixtures
}

\author{
Lars P. Kiær • Ib M. Skovgaard • \\ Hanne Østergård
}

Received: 22 August 2011/Accepted: 6 February 2012/Published online: 23 February 2012

(C) Springer Science+Business Media B.V. 2012

\begin{abstract}
Varietal seed mixtures tend to increase and stabilize crop yields, yet their application is sparse. Large-scale cultivation of variety mixtures may require a better understanding of how inter-varietal interactions and their interaction with the environment may influence the grain yield of variety mixtures relative to their component varieties. For this purpose, six variety mixtures of spring barley and 14 component varieties were grown in each of 17 trial environments. A total of 28 observed and a priori plant characteristics, including grain yield, disease severity and weed competitiveness, were derived for each component
\end{abstract}

\section{P. Kiær $(\bowtie) \cdot$ H. Østergård}

Biosystems Division, Ris $\varnothing$ National Laboratory for Sustainable Energy, Technical University of Denmark, DTU, Frederiksborgvej 399, 4000 Roskilde, Denmark e-mail: lpk@life.ku.dk

L. P. Kiær · I. M. Skovgaard

Department of Basic Sciences and Environment, University of Copenhagen, Thorvaldsensvej 40,

1871 Frederiksberg C, Denmark

\section{Present Address:}

L. P. Kiær

Department of Agriculture and Ecology, University of Copenhagen, Thorvaldsensvej 40, 1871 Frederiksberg C, Denmark

\section{Present Address:}

H. Østergård

Department of Chemical and Biochemical Engineering, Technical University of Denmark, DTU, $2800 \mathrm{Kgs}$.

Lyngby, Denmark variety in each trial. The relationship between intervarietal diversity of each characteristic and the mixing effect on grain yield was analysed. Additionally, various types of yield stability were estimated and compared among mixtures and component varieties. One mixture out-yielded all of its component varieties in almost half of the trial environments. Inter-varietal diversity in grain yield potential correlated significantly with mixing effect, as did straw length diversity when weighted with weed pressure. The grain yields of most mixtures were more stable across environments than their component varieties when accounting also for the general response to environmental productivity. Hence, most mixtures adapted slightly better to environmental productivity and were less sensitive to environmental stress than their component varieties. We conclude that the efficacy of variety mixtures may be enhanced by mixing relatively high-yielding varieties differing in responsiveness to environmental productivity.

Keywords Compensation - Complementarity · Disease severity · Environmental response . Weed infestation · Yield stability

\section{Introduction}

Growth conditions of plants vary substantially between locations and years, and it is well-known that crop varieties of cereals may differ widely in their 
response to these conditions. Such genotype-environment interactions (e.g. Finlay and Wilkinson 1963; Langer et al. 1979; Piepho 1998) are important contributors to unpredictability when breeders select genetic material and when farmers select varieties to be grown at a specific location (e.g. Allard and Bradshaw 1964; Ceccarelli 1996; Østergård et al. 2005; Wolfe et al. 2008). Yield stability is a key target in farm management, regional variety testing trials as well as crop breeding programs and has been defined and measured in a lot of different ways addressing different questions (for a review, see Robert 2002).

Seed mixtures of varieties with differing characteristics has been demonstrated as a potential means of increasing as well as stabilizing crop yield over environments (for reviews see Smithson and Lenné 1996; Finckh et al. 2000; Kiær et al. 2009). Specifically two types of interaction among the cooccurring varieties have been suggested and demonstrated to derive from such inter-varietal diversity within the crop stand, i.e. compensation and complementarity. First, varieties that perform well in a given environment may compensate the sub-optimal growth of others (e.g. Stützel and Aufhammer 1990), whether this results from inter-plant competition or environmental mismatch. Second, several types of varietal complementarity may positively affect crop yields: (a) complementarity in the strategy of varieties for utilizing natural resources (i.e. niche differentiation) may result in higher land use efficiency and generally better competitiveness against weeds, for example due to differences in height (e.g. Sage 1971; Kaut et al. 2009); (b) varietal complementarity in susceptibility to abiotic stress may result in generally higher and more stable grain yields of mixtures across growing environments (Smithson and Lenné 1996), e.g. varietal complementarity in the tendency to lodge under adverse weather conditions may allow more sturdy varieties to support the erect growth of others; and (c) varietal complementarity in resistance genes towards specific diseases has been shown to confer higher level of resistance of variety mixtures under a range of circumstances (Finckh et al. 2000); so far, the latter has been the primary reason for growing variety mixtures on commercial scale. Variety mixtures are thus expected to minimise the risk of reduced yield under stress conditions and may thus contribute to yield stability across growth environments.
Even if the observed grain yield of variety mixtures is often higher than the mean of the component yields, occasionally even outyielding the higher yielding components (Smithson and Lenné 1996), it has been found difficult to predict the effect for specific mixtures in specific years and locations (e.g. Newton and Thomas 1992; Lopez and Mundt 2000). To justify a wider use of variety mixtures in agriculture, it seems essential to pursue a better understanding of the mixing potential of specific genotypes under various growing conditions (Wolfe 2006).

The aim of this study was to investigate why some spring barley variety mixtures perform better than others relative to their component varieties. Therefore, we first assessed the yield potential and mixing effect of six variety mixtures over a broad range of environments (years, locations and crop management types). Second, we analysed the importance of diversity in various characteristics of the 14 component varieties for mixing success under the considered range of growing conditions, hypothesizing that larger mixing effects can be seen at higher levels of inter-varietal diversity. This hypothesis was put forward in a recent meta-analysis of a large number of mixtures and trials, which found that the characteristic most correlated with mixing effect was the diversity of component variety yields (Kiær et al. 2009). Third, we compared yield stability patterns of mixtures relative to pure stands of component varieties, using three different measures of stability. Ultimately, the results from the different analyses were combined to generate three hypotheses on how potential inter-varietal interactions may contribute to mixture yields and yield stability.

\section{Materials and methods}

Field trials

Field trials were conducted in the years 2002-2005 at four Danish locations: the three research stations Flakkebjerg (sandy loam), Foulum (loamy sand) and St. Jyndevad (coarse sand) and a certified organic farm at Dalmose (sandy loam). Trials represented one of three different low-input crop management strategies (Table 1). Herbicides and mineral fertilizers were applied to 'conventional' trials, whereas 'organic' trials comprised a variation of low input systems with different history of crop rotation and management. 
Table 1 Trial environments of the study

\begin{tabular}{lll}
\hline Environment $^{\mathrm{a}}$ & $\begin{array}{l}\text { No. genotypic } \\
\text { entities }\end{array}$ & $\begin{array}{l}\text { Average grain } \\
\text { yield }\left(\mathrm{hkg} \mathrm{ha}^{-1}\right)\end{array}$ \\
\hline Fou05_u & 35 & 27.4 \\
Jyn04_u & 48 & 35.3 \\
Dal05_o & 43 & 40.4 \\
Fla04_o & 48 & 42.0 \\
Jyn04_o & 48 & 47.5 \\
Fou05_o & 35 & 50.3 \\
Fou04_u & 48 & 50.6 \\
Fla02_o & 123 & 51.0 \\
Jyn03_o & 132 & 52.0 \\
Fou02_c & 119 & 52.8 \\
Fla03_o & 132 & 54.9 \\
Fou03_c & 132 & 54.9 \\
Fou03_o & 132 & 55.1 \\
Fla02_c & 119 & 56.3 \\
Fou02_o & 123 & 56.5 \\
Fou04_o & 48 & 58.5 \\
Fla03_c & 132 & 63.8 \\
\hline
\end{tabular}

a The environment coding is 3 letters for the locations Flakkebjerg, Foulum, Jyndevad and Dalmose (all in Denmark), 2 digits for year (02 denoting 2002, etc.), 1 letter for management ( $u$ undersown 'organic', $o$ 'organic', $c$ 'conventional', see text)

b Variety Culma was not grown in these environments, hence mixing effect not available for Mix2

Hence, the 'organic' systems comprised trials with or without undersown grass clover mixtures, the former with no nutrients added and the latter with a reduced rate of manure and a weed harrowing strategy including one pre-emergence weed harrowing and 1-3 rounds of postemergence weed harrowing to keep weed pressures manageable (see Hansen et al. 2008). Fungicides were not applied in any trial. A total of 17 combinations of year, location and management were included in this study (Table 1), hereafter designated as environments. Field plots were rectangular strips of width $1.5 \mathrm{~m}$, with an area varying among trials from 12 to $20 \mathrm{~m}^{2}$. Between 35 and 132 varieties and variety mixtures of spring barley (hereafter designated genotypic entities) were grown in each environment (Table 1). Each trial was laid out in an incomplete block design ( $\alpha$-design, Patterson et al. 1978) with two or three replicates. Each trial was analysed with a mixed effects model,

$Y_{i j k l}=\mu_{i l}+C_{k l}+D_{j k l}+E_{i j k l}$,

where $Y_{i j k l}$ is the observed grain yield of the $i$ th of $v$ genotypic entities in the $j$ th of $b$ blocks in the $k$ th of $r$ replicates in environment $l, \mu_{i l}$ is the expected mean yield of genotypic entity $i$ in environment $l$, while $C_{k l}$, $D_{j k l}$ and $E_{i j k l}$ are random effects of replicate, block within replicate, and residual error, each assumed to be iid normally distributed with mean value 0 and variances $\sigma_{C}^{2}, \sigma_{D}^{2}$ and $\sigma_{E}^{2}$, respectively.

\section{Varieties and mixtures studied}

Each of the six considered variety mixtures were composed of three component varieties from a set of 14 (Table 2). The varieties and mixture combinations were selected to study interactions between component varieties and the influence of variation in varietal characteristics for mixture performance, specifically with respect to height and weed competitiveness. For this reason, mixture components were chosen to have generally high disease resistance and larger than recommended inter-varietal differences in straw length. Further, some mixtures combined malting and fodder varieties. It is important to note that the mixtures were not designed to maximise mixing effects or to study the control of disease resistance. In order to ensure acceptable agronomic performance all mixtures complied with the official Danish certification requirements for mixture components concerning relative yield, disease resistance, and date of ripening (see Østergård and Jensen 2005). One older variety (Culma) was not grown in two of the environments, and the effect of mixing could not be estimated in these environments for the mixture (Mix2) to which it contributed.

\section{Analysis of mixing effect}

In order to level out differences in productivity among trial environments and the resulting variation in errors, which were observed to affect comparisons of absolute values of yield in mixture and pure stand plots, a relative measure of mixing effect was calculated for each mixture in each environment by a relative effect measure as

$\operatorname{MErel}_{m l}=\frac{\hat{\mu}_{l}^{m}-\hat{\mu}_{m l}^{c}}{\hat{\mu}_{m l}^{c}}$,

where $\hat{\mu}_{l}^{m}$ is the estimated mean yield of mixture $m$ in environment $l$ and $\hat{\mu}_{m l}^{c}=\sum_{i(m)}\left(\hat{\mu}_{i l} / 3\right)$ is the mean of the estimated mean yields of its three component varieties in pure stand in the given environment, as 
Table 2 A priori characteristics of each component variety (mixture membership indicated in parentheses) and the corresponding indices of inter-varietal diversity for each mixture (see text)

\begin{tabular}{|c|c|c|c|c|c|c|c|}
\hline & $\begin{array}{l}\text { Grain yield } \\
(1-5)^{\mathrm{b}}\end{array}$ & $\begin{array}{l}\text { Mildew } \\
(0-3)^{c}\end{array}$ & $\begin{array}{l}\text { Leaf rust } \\
(0-3)^{c}\end{array}$ & $\begin{array}{l}\text { Net blotch } \\
(0-3)^{\mathrm{c}}\end{array}$ & $\begin{array}{l}\text { Scald } \\
(0-3)^{c}\end{array}$ & $\begin{array}{l}\text { Straw length } \\
(1-5)^{\mathrm{b}}\end{array}$ & $\begin{array}{l}\text { Weed suppres- } \\
\text { siveness }(\%)\end{array}$ \\
\hline \multicolumn{8}{|c|}{ Varietal characteristics } \\
\hline Alabama (3) & 3 & 0 & 1 & 2 & 2 & 1 & 19.2 \\
\hline Brazil $(2,4)$ & 4 & 2 & 2 & 2 & 1 & 2 & 25.2 \\
\hline Cicero $(2,6)$ & 3 & 0 & 2 & 1 & 2 & 2 & 23.9 \\
\hline Culma $^{a}(2)$ & - & - & - & - & - & - & - \\
\hline Danuta (4) & 3 & 0 & 1 & 2 & 2 & 5 & 49.0 \\
\hline Fabel $(5,6)$ & 3 & 0 & 0 & 0 & 2 & 4 & 36.4 \\
\hline Harriot (5) & 3 & 1 & 0 & 1 & 2 & 4 & 37.2 \\
\hline Landora (1) & 3 & 0 & 2 & 1 & 0 & 4 & 29.5 \\
\hline Neruda (3) & 3 & 0 & 2 & 3 & 2 & 3 & 27.7 \\
\hline Orthega $(1,4)$ & 2 & 2 & 0 & 1 & 1 & 4 & 38.5 \\
\hline Otira (1) & 4 & 0 & 2 & 2 & 2 & 2 & 31.3 \\
\hline Prestige (3) & 3 & 0 & 1 & 3 & 1 & 3 & 27.6 \\
\hline Punto (6) & 2 & 0 & 1 & 2 & 1 & 2 & 25.0 \\
\hline Sebastian (5) & 4 & 3 & 1 & 2 & 1 & 2 & 18.9 \\
\hline \multicolumn{8}{|c|}{ Inter-varietal diversity } \\
\hline Mix 1 & 1 & 1.16 & 1.16 & 0.58 & 1 & 1.16 & 4.8 \\
\hline $\operatorname{Mix} 2^{a}$ & - & - & - & - & - & - & - \\
\hline Mix3 & 0 & 0 & 0.58 & 0.58 & 0.58 & 1.16 & 4.9 \\
\hline Mix4 & 1 & 1.16 & 1 & 0.58 & 0.58 & 1.53 & 11.9 \\
\hline Mix5 & 0.58 & 1.53 & 0.58 & 1 & 0.58 & 1.16 & 10.3 \\
\hline Mix6 & 0.58 & 0 & 1 & 1 & 0.58 & 1.16 & 6.9 \\
\hline
\end{tabular}

${ }^{a}$ No a priori information was available for the variety Culma

b All growth potential indices: 1 (very low) to 5 (very high)

c All disease susceptibility indices: 0 (resistant) to 3 (very susceptible)

obtained from Eq. 1. Another measure of mixing effect, the extent to which mixtures were able to match the performance of the highest-yielding component variety in a given environment was found as

$\operatorname{MEmax}_{m l}=\frac{\hat{\mu}_{l}^{m}-\hat{\mu}_{m l}^{\max }}{\hat{\mu}_{m l}^{\max }}$,

where $\hat{\mu}_{m l}^{\max }$ is the maximal estimated pure stand mean yield for any component variety of mixture $m$ in environment $l$, as obtained from Eq. 1 .

\section{Inter-varietal diversity}

In order to quantify for each mixture in each environment the inter-varietal diversity with respect to a number of plant characteristics, the standard deviation among component varieties for each characteristic was calculated as
$\mathrm{D}(x)_{m l}=\sqrt{\frac{\sum_{i=1}^{3}\left(x_{i l}-\bar{x}_{\cdot l}\right)^{2}}{3-1}}$,

where $x_{i l}$ is the value of component variety $i$ in environment $l$ and $\bar{x}_{. l}$ is the mean value of all components of mixture $m$ in that environment. A priori characteristics from external sources as well as pure stand observations in each of the 17 trials were obtained. Seven a priori characteristics on the potential performance of component varieties were derived from a national database (Table 2; for further details, see Østergård et al. 2008). These included index values for grain yield potential, susceptibility towards each of the four prevailing foliar diseases: powdery mildew (Blumeria graminis), leaf rust (Puccinia hordei), net blotch (Pyrenophora teres), and scald (Rhynchosporium secalis), and straw length potential measured under weed and disease free conditions. In addition, values 
on the potential weed suppressiveness (\%) were obtained from Hansen et al. (2008), describing the average reduction in weed coverage in the plots of each variety compared to the $90 \%$ quantile based on all single-plot observations of that study.

A number of variety characteristics were observed in the studied environments, of which eight corresponded to the assessed a priori characteristics: harvested grain yield (at 85\% dry matter), disease severity of each of the four prevailing foliar diseases (in $\%$ leaf area infected), infestation by tall annual weeds and creeping weeds, respectively (each in \% ground cover; see Østergård et al. 2008), as well as straw length (after flowering, in $\mathrm{cm}$ ). Assessments were detailed enough for predicting yield loss from a priori disease and weed competitiveness information, as shown by Østergård et al. (2008). Additionally, recorded dates of plant emergence, heading and maturity were used as variety characteristics (relative to the sowing date as number of days-until-emergence, number of days-until-heading, and number of daysuntil-maturity, respectively). Lodging was measured but the data were not appropriate for statistical analysis. All characteristics were observed for each genotype in each replicate, and genotypic means were estimated from models such as that in Eq. 1. Weed levels were not observed in the conventionally managed trials so these were all set to zero, assuming that the herbicide treatment was fully effective. The estimates of disease severity and ground cover of weeds for each genotype in each environment were third root transformed to optimize distributional properties prior to further analysis in analogy with previous analyses of the present data (cf Østergård et al. 2008).

\section{Regression on inter-varietal diversity}

For all a priori characteristics except grain yield potential, the effect of inter-varietal diversity on the yield of a given mixture in a given environment was likely to depend on biotic stresses, i.e. the environmental loads of the diseases or weeds of importance for the potential expression of the characteristic. Where relevant, estimates of inter-varietal diversity were therefore multiplied with the corresponding environmental load prior to regression in order to provide a weighted covariate. This procedure was similar to the methodology used by Østergård et al. (2008) for the prediction of variety characteristics. The loads applied were $95 \%$ percentiles of all single plot observations in each environment (data from Østergård et al. 2008).

For most of the observed characteristics, actual environmental load was already part of the observation and the regression was done without environmental loads. For effects of inter-varietal diversity in observed straw length and phenological characteristics, however, a potential dependency on the environmental weed loads was hypothesized and correspondingly tested (see Table 3 for a list of all tested combinations).

The relationships between mixing effect and each type of inter-varietal diversity were analysed using a mixed model linear regression model of the general form

$\operatorname{MErel}_{m l}=\delta_{m l}+\beta_{m} * Z_{m l}+F_{m}+G_{l}+H_{m l}$,

where $\operatorname{MErel}_{m l}$ is obtained from Eq. 2, $\delta_{m l}$ is the expected mean mixing effect, $\beta_{m}$ is the regression coefficient on $Z_{m l}$, and $F_{m}, G_{l}$ and $H_{m l}$ are random effects of mixture, environment and residual error, respectively. Depending on the trait, $Z_{m l}$ equals the inter-varietal diversity $\mathrm{D}(x)_{m l}$ or its product with environmental load $L_{l}$ (as described above).

Estimation of parameters was done by log-likelihood maximization, and the effect of each type of intervarietal diversity was tested by likelihood ratio test against the intercept-only model $\left(\beta_{m}=0\right)$. Variation in mixing effect within each of the three management systems was as large as between them, e.g. the 'organic' environments ranked between third and sixteenth with respect to yield level. Therefore, genotypic performances were not compared between systems and instead the 17 environments were considered as representing large environmental variation.

The amount of variation explained by the covariate was assessed by a coefficient of determination, comparing total variance of the random effects in the covariate model with that in the intercept-only model as

$$
\begin{aligned}
R^{2} & =1-\frac{\sum \hat{\sigma}_{(c)}^{2}}{\sum \hat{\sigma}_{(0)}^{2}} \\
& =1-\frac{\sum \hat{\sigma}_{F(c)}^{2}+\sum \hat{\sigma}_{G(c)}^{2}+\sum \hat{\sigma}_{H(c)}^{2}}{\sum \hat{\sigma}_{F(0)}^{2}+\sum \hat{\sigma}_{G(0)}^{2}+\sum \hat{\sigma}_{H(0)}^{2}},
\end{aligned}
$$

where $(c)$ denotes variance components from the covariate model, (0) denotes variance components from the intercept-only (null) model, and letters $F$, $G$ and $H$ denote the variance components of the random terms in Eq. 5. Since total variance in the covariate model may become larger than that of 
Table 3 Results of mixed model regression of mixing effect against each type of inter-varietal diversity, of which some characteristics are weighted by environmental loads (see text)

For each relationship are provided regression coefficient estimates $(\beta$, given in $\%$ point $)$, test probabilities from likelihood ratio tests $\left(P_{\mathrm{LRT}}\right)$, and the coefficients of determination $\left(R^{2}\right)$

a Negative regression coefficient estimates indicate that mixing effect decreases with increasing inter-varietal diversity

b Probability levels are designated as bold $(<5 \%)$ or italic $(<10 \%)$

\begin{tabular}{|c|c|c|c|c|}
\hline Inter-varietal diversity of & Environmental load & $\beta(\%)^{\mathrm{a}}$ & $P_{\mathrm{LRT}}^{\mathrm{b}}$ & $R^{2}(\%)$ \\
\hline \multicolumn{5}{|l|}{ A priori } \\
\hline Grain yield potential & - & 3.223 & 0.04 & 7.6 \\
\hline Mildew susceptibility & Mildew & 0.009 & 0.80 & 0.1 \\
\hline Leaf rust susceptibility & Leaf rust & 0.718 & 0.26 & 6.0 \\
\hline Net blotch susceptibility & Net blotch & 0.031 & 0.78 & 0.3 \\
\hline Scald susceptibility & Scald & -0.012 & 0.96 & 0.0 \\
\hline Straw length potential & Tall weeds & 0.022 & 0.39 & 1.4 \\
\hline Straw length potential & Creeping weeds & -0.010 & 0.53 & 0.7 \\
\hline Weed suppressiveness & Tall weeds & 0.002 & 0.57 & 0.9 \\
\hline Weed suppressiveness & Creeping weeds & -0.002 & 0.36 & 0.7 \\
\hline \multicolumn{5}{|l|}{ Observed } \\
\hline Grain yield & - & 0.297 & 0.30 & 3.0 \\
\hline Mildew disease severity & - & 0.058 & 0.96 & 0.0 \\
\hline Leaf rust disease severity & - & 7.410 & 0.33 & 6.0 \\
\hline Net blotch disease severity & - & 2.618 & 0.11 & -0.4 \\
\hline Scald disease severity & - & 4.257 & 0.16 & 1.7 \\
\hline Tall annual weeds infestation & - & -5.666 & 0.07 & 4.2 \\
\hline Creeping weeds infestation & - & 1.712 & 0.51 & 1.0 \\
\hline Straw length & - & 0.271 & 0.11 & 3.7 \\
\hline Straw length & Tall annual weeds & 0.036 & 0.02 & 3.8 \\
\hline Straw length & Creeping weeds & 0.012 & 0.16 & -5.3 \\
\hline Days-to-heading & - & -0.049 & 0.89 & 0.1 \\
\hline Days-to-heading & Tall annual weeds & 0.003 & 0.71 & 0.1 \\
\hline Days-to-heading & Creeping weeds & -0.003 & 0.65 & 0.4 \\
\hline Days-to-maturity & - & -0.256 & 0.55 & 0.4 \\
\hline Days-to-maturity & Tall annual weeds & 0.006 & 0.67 & 0.1 \\
\hline Days-to-maturity & Creeping weeds & -0.008 & 0.20 & 1.9 \\
\hline Days-to-emergence & - & 1.440 & 0.40 & 2.1 \\
\hline Days-to-emergence & Tall annual weeds & 0.009 & 1.00 & 0.3 \\
\hline Days-to-emergence & Creeping weeds & 0.008 & 0.79 & -0.4 \\
\hline
\end{tabular}

the intercept-only model, $R^{2}$ may become negative and is then interpreted as zero.

\section{Yield stability across environments}

Three concepts of genotype stability were applied. For static stability sensu Lin et al. (1986), an environmental variance was defined for each genotypic entity $i$ as the variance of yields of genotypic entities across recorded trial environments:

$s_{i}^{2}=\frac{\sum_{l}\left(\hat{\mu}_{i l}-\hat{\mu}_{i \cdot}\right)^{2}}{17-1}$,

where $\hat{\mu}_{i l}$ is the estimated grain yield of genotypic entity $i$ in trial environment $l$ and $\hat{\mu}_{i}$. is the mean yield of the genotypic entity across the 17 trial environments. For this measure, largest stability is seen at small $s_{i}^{2}$ values.

A dynamic measure of genotype stability (sensu Lin et al. 1986), describing the adaptability of genotypes (i.e. their responsiveness to environmental productivity), was obtained from the linear regression model

$\hat{\mu}_{i l}=a_{i}+b_{i} \cdot \hat{\mu}_{\cdot l}+d_{i l}$,

where $a_{i}$ is the intercept, $b_{i}$ is the regression coefficient of genotypic entity $i, \hat{\mu}_{. l}$ is the expected mean yield of all genotypic entities grown in trial environment $l$ (Table 1), being used as the best available estimate of productivity in each environment, and $d_{i l}$ is used to denote error, being deviations from the fitted 
regression line. Regression coefficients $b_{i}$ then describe the ability of a genotypic entity to respond to environmental productivity, with an average coefficient of responsiveness corresponding to $b_{i}=1$, following the average level of environmental interaction of all the varieties considered. A genotype with $b_{i}=1$ is considered as possessing average responsiveness to environmental conditions (Finlay and Wilkinson 1963). Higher responsiveness is then found at $b_{i}>1$, and lower responsiveness is found at $b_{i}<1$. Hypotheses that $b_{i}=1$ and $b_{i 1}=b_{i 2}$ were tested by $t$-tests.

The variance of deviations from the regression model in Eq. 8, $s\left(d_{i}\right)^{2}$, was used as a third measure of stability describing the sensitivity of genotypic entities to biotic and abiotic environmental factors apart from those defining general environmental productivity.

\section{Results}

Relative mixing effects

The average mixing effect was $1.9 \%$ (an average increase of $0.9 \mathrm{hkg} \mathrm{ha}^{-1}$ ), which was significantly different from 0 ( $t$-test, $P<0.001)$ for all mixtures across all trial environments, with lower and upper quartiles of mixing effect being -0.8 and $4.4 \%$, respectively. Individual mixing effects ranged from -12.5 to $15.5 \%$ (Fig. 1a), varying significantly between mixtures $(P<0.05)$ and between trial environments $(P<0.05)$ when considering both as fixed effects in a simple analysis of variance. The average mixing effect was significantly positive in three of the six mixtures. Mix 1 provided the highest average mixing effect of $4.0 \%(P<0.001)$, corresponding to an average increase of $2.1 \mathrm{hkg} \mathrm{ha}^{-1}$. The mixing effects of this mixture were almost exclusively positive (except a value of $-0.3 \%$ in one environment), indicating that it yielded consistently more than the average of its components across all environments (Fig. 1a). Mix5 and Mix6 provided significant mixing effects of $2.4 \%(P<0.05)$ and $2.9 \%(P<0.01)$, corresponding to average increases of 1.3 and $1.2 \mathrm{hkg} \mathrm{ha}^{-1}$, respectively (Table 4). The other mixtures provided insignificant average mixing effects. Given the incomplete use of management systems across locations and years, these factors were considered to be potentially confounded and could therefore not be tested.
Effects of inter-varietal diversity

Only two of 28 tested linear relationships between inter-varietal diversity and mixing effect were significant (Table 3), namely (1) straw length weighted by load of tall annual weeds $(P=0.02)$ and (2) grain yield potential $(P=0.04)$. All but one of the diseaserelated characteristics (based on a priori as well as observed component variety characteristics) had positive but insignificant relationships to mixing effect, yet, inter-varietal diversity in leaf rust susceptibility and observed leaf rust severity both explained some variation in mixing effect $\left(R^{2}=6.0 \%\right.$ in both cases). No relationship with any inter-varietal diversity in phenology was found.

The first of the significant relationships showed that increased height diversity in the crop stand confers increased yields when competing with weeds of the tall annual type. A positive relationship with mixing effect was also suggested for inter-varietal diversity in straw length, although this relationship was not significant (Table 3). The relationship between mixing effect and the related (and oppositely directed) inter-varietal diversity in observed infestation by tall annual weeds was negative and almost significant $(P=0.07)$, suggesting that the yield advantage of growing varieties in mixtures was smaller when their ability to suppress these weeds (i.e. as observed in pure stand) was more diverse. The relationships between mixing effect and each of the corresponding types of inter-varietal diversity, straw length potential and weed suppressiveness, were far from significant (Table 3).

The second of the significant relationships showed that mixing effects were higher when mixing varieties more diverse in grain yield potential. Likewise, intervarietal diversity in observed grain yield, generally termed $\mathrm{D}(\hat{\mu})$, had a positive relationship with mixing effect (Table 3). However, despite the overall increase in mixing effect with larger yield differences among component pure stand yields, as indicated also in Fig. 2a, the relationship was not significant $(P=$ 0.30). Mainly, Mix5 and Mix6 contributed to this putative relationship, whereas Mix 1 (with the largest mixing effect) did not (Fig. 2a). On the other hand, $\mathrm{D}(\hat{\mu})$ was significantly related to mixture performance in terms of outyielding of component varieties, $\operatorname{MEmax}_{m l}$. Overall, significantly higher values of $\operatorname{MEmax}_{m l}$ were found at lower values of $\mathrm{D}(\hat{\mu})\left(\beta_{m}=\right.$ $-0.013 ; P<0.001$; least squares regression). Hence, 

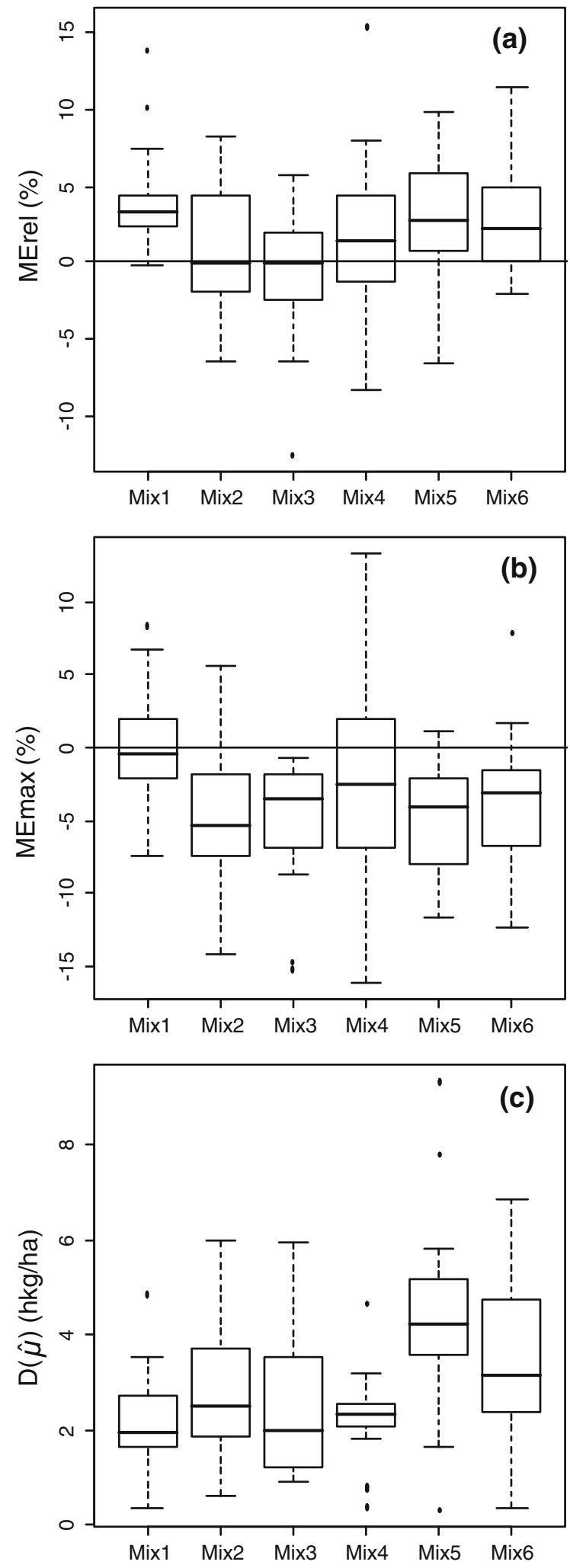

4 Fig. 1 Mixture-wise boxplots of a relative mixing effects, b mixture yield relative to highest yielding component, and c $\mathrm{D}\left(\hat{\mu}_{i}\right)$. For each mixture is shown the median (thick vertical lines), lower and upper quartiles (lower and upper ends of boxes), standard deviations (whiskers), and extreme values (black dots) among the 17 environments

mixtures were generally more likely to outyield the highest yielding component $\left(\operatorname{MEmax}_{m l}>0\right)$ when the components had more similar yields (low values of $\mathrm{D}(\hat{\mu})$; see Fig. 2b). Mix 1 provided a higher yield than (outyielded) all of its component varieties in 8 environments, whereas for the other mixtures this effect was much less pronounced, occurring in only 3 , $0,5,1$ and 3 of the environments, respectively (Figs. 1b, 2b). As seen from the lower values of $\mathrm{D}(\hat{\mu})$ (Fig. 1c), the component varieties in each of mixtures 1,3 and 4 generally had more similar yields in each environment than the component varieties of Mix5 and Mix6 (all $P<0.05$ in pairwise $t$-test with adjustment for multiple comparisons) whereas values of Mix 2 were not different from those in any of the other mixtures (Fig. 1c). The $\mathrm{D}(\hat{\mu})$ of Mix 4 were particularly similar across growth environments, as seen from the small inter-quartile range.

Yield and stability analysis

Average grain yield levels ranged from 48.6 to $53.7 \mathrm{hkg} \mathrm{ha}^{-1}$ for mixtures and from 45.1 to $52.1 \mathrm{hkg} \mathrm{ha}^{-1}$ for component varieties in pure stand (Table 4). Among all genotypic entities, the highest average yield level was found in Mix 1 and the lowest in the variety Fabel. It is seen by plotting grain yields of each mixture and its component varieties separately against average environment yields (Table 1; Fig. 3) that Mix1 outyielded its components in the four environments with the highest levels of productivity (Fig. 3a). One of the component varieties (Harriot) of Mix 5 yielded generally higher than the mixture and the other components across the range of environmental productivity (open squares in Fig. 3e); yet, under higher levels of environmental productivity the yield of Mix 5 approached that of Harriot and occasionally exceeded it. Mix6 yielded generally well, having higher yields than each of its components in pure stand under less productive conditions (Fig. 3f). In only one mixtureenvironment combination did the mixture provide a considerably lower yield than all of its components (Mix3, with a yield of app. $35 \mathrm{hkg} \mathrm{ha}^{-1}$; Fig. 3c). 
Table 4 Grain yield level $\left(\hat{\mu}_{i}\right)$ and measures of yield stability $\left(s_{i}{ }^{2}, b_{i}, s\left(d_{i}\right)^{2}\right)$ of each component variety and variety mixture across environments a Mixture membership of varieties provided in parentheses

b Component means in italics and parentheses below each mixture value

\begin{tabular}{|c|c|c|c|c|}
\hline & $\hat{\mu}_{i}\left(\mathrm{hkg} \mathrm{ha}^{-1}\right)$ & $s_{i}^{2}\left(\mathrm{hkg}^{2} \mathrm{ha}^{-2}\right)$ & $b_{i}$ & $s\left(d_{i}\right)^{2}\left(\mathrm{hkg}^{2} \mathrm{ha}^{-2}\right)$ \\
\hline \multicolumn{5}{|l|}{ Varieties $^{\mathrm{a}}$} \\
\hline Alabama (3) & 48.0 & 5.67 & 1.07 & 3.45 \\
\hline Brazil $(2,4)$ & 49.9 & 5.00 & 1.03 & 2.55 \\
\hline Cicero $(2,6)$ & 50.0 & 6.24 & 1.15 & 3.24 \\
\hline Culma (2) & 47.9 & 5.61 & 0.98 & 2.16 \\
\hline Danuta (4) & 52.0 & 5.42 & 1.08 & 2.25 \\
\hline Fabel $(5,6)$ & 45.1 & 3.68 & 0.85 & 3.58 \\
\hline Harriot (5) & 52.1 & 4.88 & 1.02 & 2.53 \\
\hline Landora (1) & 51.9 & 6.79 & 1.18 & 3.07 \\
\hline Neruda (3) & 50.6 & 5.35 & 1.06 & 2.90 \\
\hline Orthega $(1,4)$ & 51.3 & 5.25 & 1.06 & 2.51 \\
\hline Otira (1) & 51.6 & 4.63 & 0.99 & 2.27 \\
\hline Prestige (3) & 49.2 & 5.05 & 1.05 & 1.71 \\
\hline Punto (6) & 47.1 & 4.66 & 1.01 & 1.52 \\
\hline Sebastian (5) & 48.6 & 5.06 & 1.00 & 3.14 \\
\hline Varieties mean & 49.9 & 5.21 & 1.04 & 2.60 \\
\hline \multicolumn{5}{|l|}{ Mixtures $^{\mathrm{b}}$} \\
\hline \multirow[t]{2}{*}{ Mix 1} & 53.7 & 5.90 & 1.13 & 1.87 \\
\hline & $(51.6)$ & $(5.56)$ & (1.08) & $(2.62)$ \\
\hline \multirow[t]{2}{*}{ Mix2 } & 49.8 & 6.19 & 1.10 & 1.61 \\
\hline & $(49.3)$ & $(5.62)$ & $(1.05)$ & $(2.65)$ \\
\hline \multirow[t]{2}{*}{ Mix3 } & 49.0 & 5.64 & 1.11 & 2.04 \\
\hline & $(49.3)$ & $(5.36)$ & $(1.06)$ & $(2.69)$ \\
\hline \multirow[t]{2}{*}{ Mix4 } & 52.0 & 6.31 & 1.13 & 3.22 \\
\hline & $(51.1)$ & $(5.22)$ & $(1.06)$ & $(2.44)$ \\
\hline \multirow[t]{2}{*}{ Mix 5} & 49.8 & 5.04 & 1.04 & 2.10 \\
\hline & $(48.6)$ & $(4.54)$ & $(0.96)$ & $(3.08)$ \\
\hline \multirow[t]{2}{*}{ Mix6 } & 48.6 & 4.05 & 0.94 & 1.69 \\
\hline & $(47.4)$ & $(4.86)$ & $(1.00)$ & $(2.78)$ \\
\hline Mixtures mean & 50.4 & 5.49 & 1.08 & 2.06 \\
\hline
\end{tabular}

In the following, the three stability estimates of each genotypic entity are considered (Table 4). First, the environmental variance, $s_{i}^{2}$, of all mixtures except one (Mix4) was within the range of their component varieties. The environmental variance of the variety Fabel was the lowest of any of the considered genotypes. Second, for most mixtures and component varieties the responsiveness to environmental productivity was higher than the average of all genotypes grown in the field trials (as indicated by regression coefficients $b_{i}$ larger than 1 ). The regression coefficients of five mixtures were non-significantly larger than the average coefficients of their components and non-significantly larger than 1 ( $t$-tests; not shown). The regression coefficient of Mix6 was smaller than the average of its components by 0.06 and numerically smaller than 1, only being higher than its component Fabel. Fabel furthermore had the lowest average yield among genotypic entities, indicating that this variety had a relatively higher adaptability to low-yielding environments (as seen from the lower left-most position in Fig. 4). Conversely, Mix 1 and its component Landora showed the highest levels of responsiveness to high environmental productivity (as seen from their upper-right-most position in Fig. 4). Third, the variance of deviations from the regression line, $s\left(d_{i}\right)^{2}$, was generally lower for mixtures than for pure stand varieties, indicating that mixtures were less sensitive to biotic and abiotic stresses. One of the mixtures (Mix4) was significantly more sensitive than 

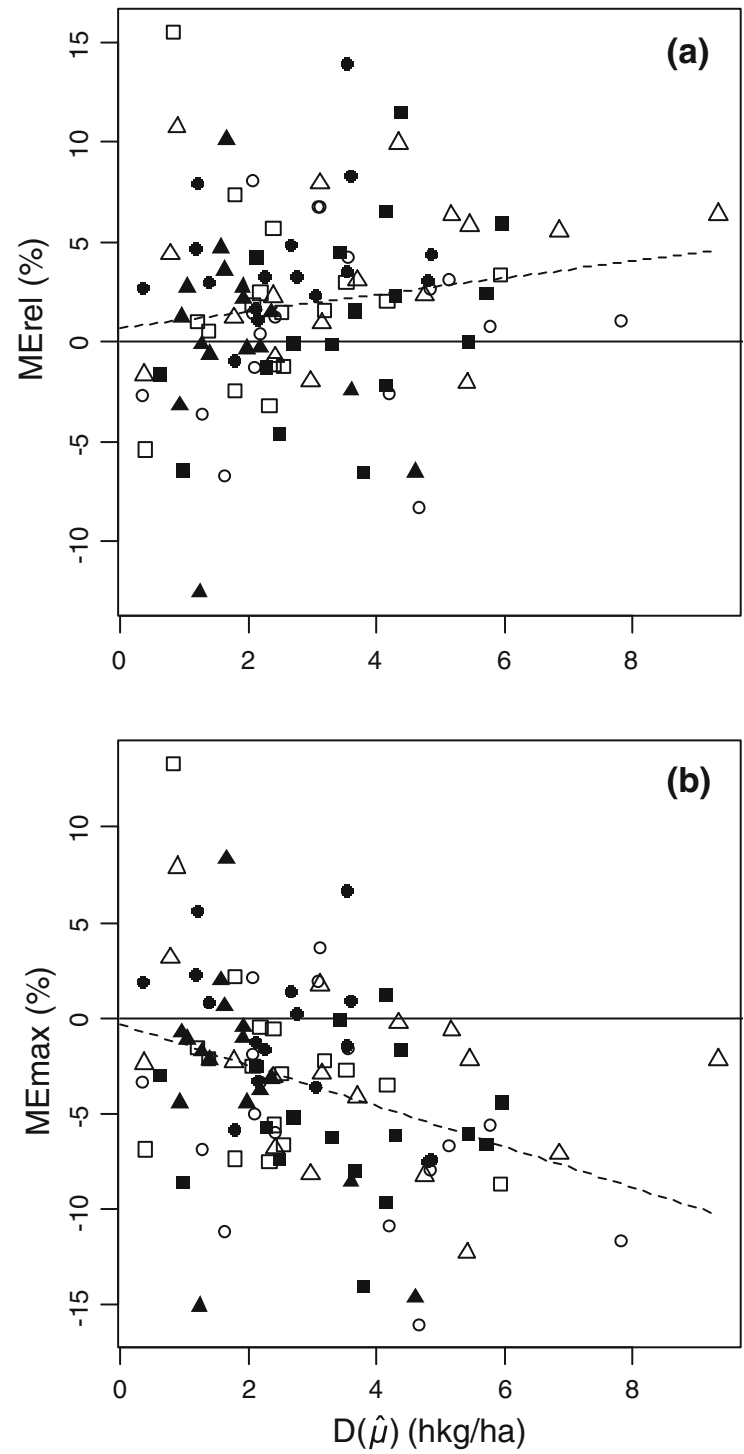

Fig. 2 Linear regressions of a relative mixing effect and b mixture yield relative to highest yielding component against the standard deviation of component variety yields in each environment. Individual data points are shown for Mix 1 (full circles), Mix 2 (full squares), Mix 3 (full triangles), Mix 4 (open circles), Mix 5 (open squares), and Mix 6 (open triangles)

any of the remaining mixtures and most of the pure stand varieties $(P<0.001 ; z$-test $)$, as seen in Fig. $3 \mathrm{~d}$. The variety Punto (component of Mix6) showed the lowest level of sensitivity of all genotypic entities, including mixtures, whereas the variety Fabel (component of Mix5 and Mix6) showed the very highest level of sensitivity. When disregarding the latter, the group of mixtures was found to be significantly more resilient than the group of component varieties $(P=$ 0.016 ; $t$-test).

\section{Discussion}

Effects of inter-varietal diversity

Among all types of inter-varietal diversity, yield potential diversity had the largest influence on mixing effect (i.e. largest coefficient of determination, Table 3), thereby confirming previous findings from a literature survey on variety mixtures of wheat and barley (Kiær et al. 2009). Furthermore, the relative mixing effect was generally higher among varieties of more diverse height and more so in the presence of tall annual weeds. This supports the hypothesis that mixtures of varieties of varying straw length have an actual advantage in terms of weed suppression (Kaut et al. 2009). Interestingly, mixing effects tended to be smaller when the level of suppression of tall annual weeds by component varieties was more diverse. This indicated that the yield advantage of mixing varieties is lower if one component is particularly effective or particular poor at suppressing these weeds.

Few types of inter-varietal diversity were thus correlated with mixing effect, even when accounting for relevant environmental loads (Table 3). The finding that most mixtures (all except Mix4) were less sensitive to biotic and abiotic environmental stresses than most of their component varieties suggests the contrary. A number of possible explanations are therefore worthwhile considering. First, grain yield is the ultimate result of multiple genotype-environment interactions, and differences in harvested grain yield can therefore be seen as a composite descriptor of the complex inter-varietal diversity that is insufficiently described by single factors. Hence, mixing effect could be the result of many small effects, each of which was too small to detect with the current analysis and experimental set-up. Second, the observed variation in mixing effect could be strongly influenced by characteristics and factors other than those considered. As an example, below-ground characteristics and interactions are often of greater importance for plant performance than those above ground (e.g. Wilson 1988) but are usually difficult to observe; root length and root biomass of the component varieties grown hydroponically were found to have a positive relationship with 
Fig. 3 Grain yields of mixtures (black dots) and their component varieties (open triangles, open circles and open squares) plotted against environmental mean yields (a Mix 1; b Mix2 etc.). Component names provided as the first two letters in each name. Broken lines indicate average stability

(i.e. regression line with $a=0, b=1$ )
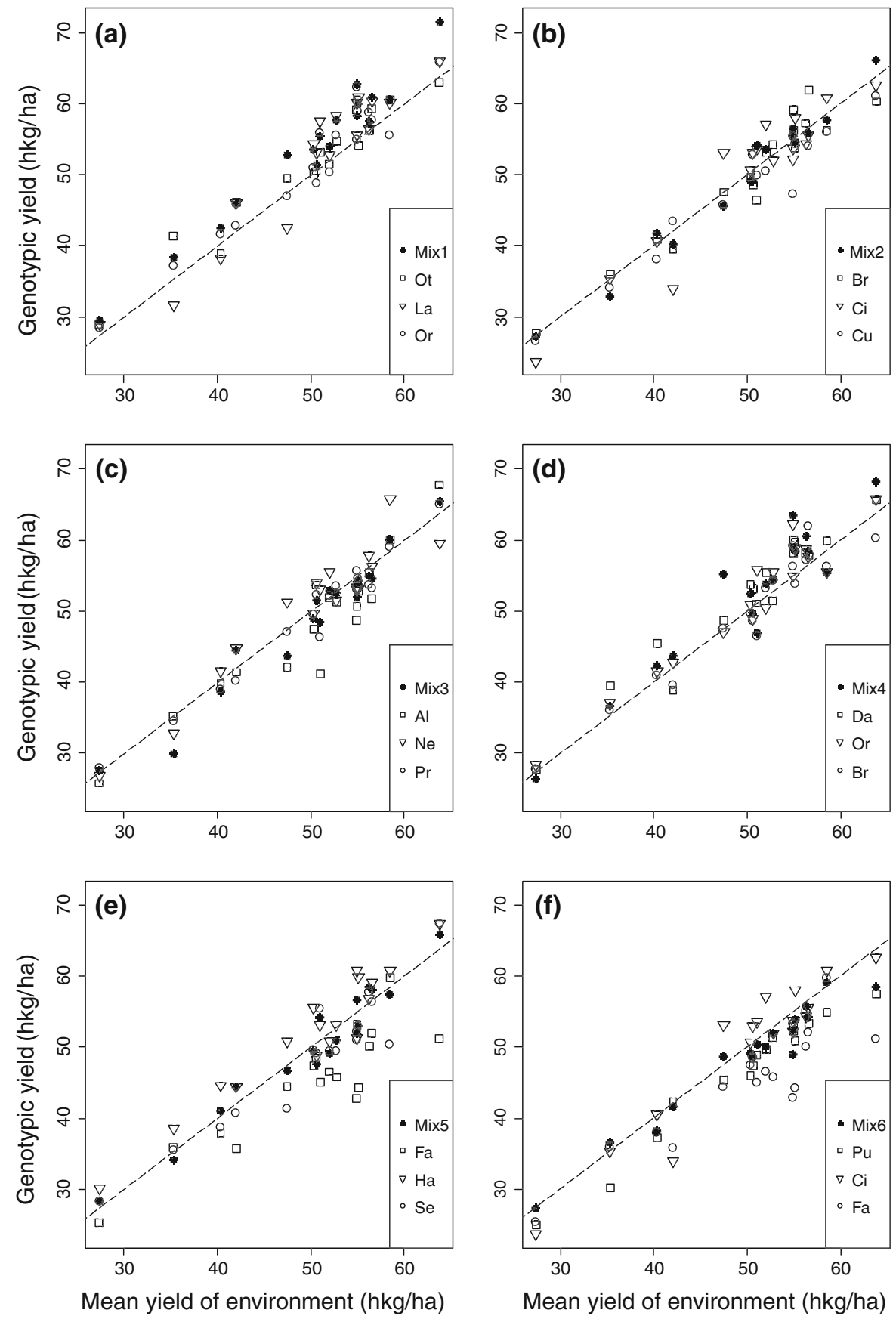

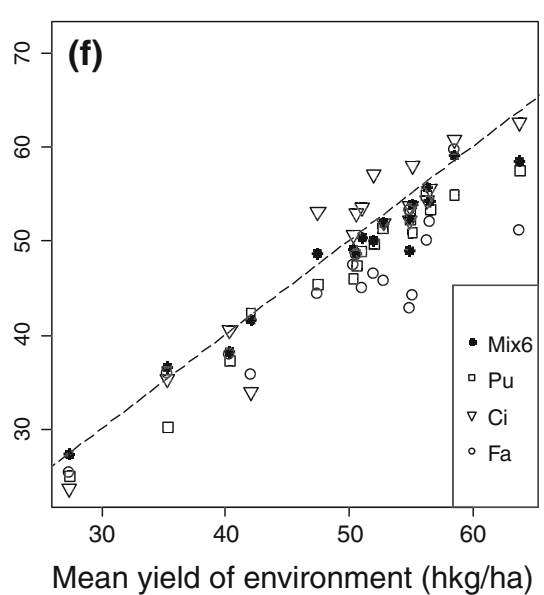

mixing effect (pers. comm., N.-O. Bertholdsson). Third, whereas most of the trials in the present study were organic or low-input, the a priori characteristics used were based on VCU tests under conventional cultivation and may not be optimal for describing interactions in the studied environments. Last, some of the observed varietal characteristics may have been biased by interplot interference, as discussed below.

Inter-varietal diversity in disease resistance genes is well documented as an effective means of controlling fungal pathogens and stabilizing yield under disease in variety mixtures (Smithson and Lenné 1996; Finckh 


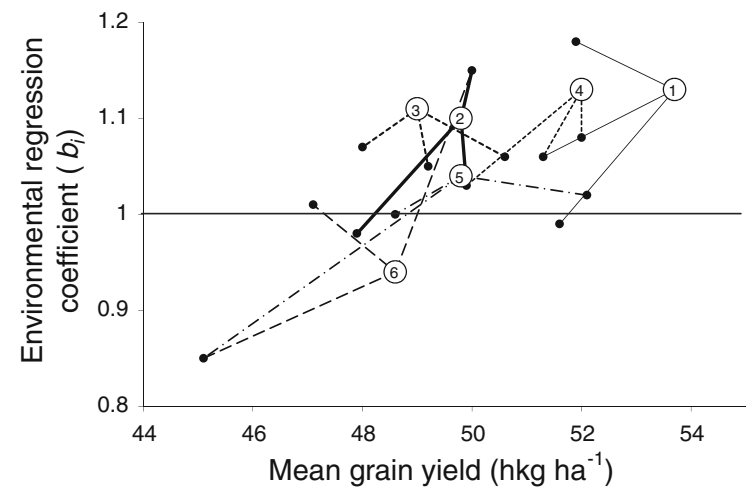

Fig. 4 Average grain yields plotted against environmental regression coefficients of variety mixtures 1-6 (numbered circles) and their component varieties (black dots), respectively (connected by lines)

et al. 2000; Newton et al. 2002). In practice, the largest proportion of commercial variety mixtures is grown for the purpose of fungal disease control. In Denmark, official certification procedures for variety mixtures set minimum requirements with respect to the disease resistance of component varieties (Østergård and Jensen 2005). The mixtures were selected to follow these requirements, which implied relatively little inter-varietal diversity in disease susceptibility and severity (not shown), which in turn may have been the cause of the low correlation with mixing effect. A number of other circumstances may have contributed to this lack of significant relationships. First, the applied disease susceptibility scores (0-3) may be too simple to be used as predictors of disease development in mixtures, e.g. two component varieties may have the same low susceptibility score due to different resistance genes, so that in a specific environment only one of the components may be resistant to the actual pathogen strain; the weighting by environmental disease load would not be able to compensate for this. Second, simultaneous infection by multiple pathogens may have had a non-additive yield effect. As an example, when all traits in the full data set were combined and weighted with observed disease loads of powdery mildew, leaf rust and net blotch, a nonadditive effect of powdery mildew and leaf rust on grain yield of varieties was found (Østergård et al. 2008). In the present study, the actual data were considered too sparse for such an approach. Last, the observed disease levels may have been biased by interplot interference, a well-studied phenomenon in which neighbouring plots as well as whole-trial plot diversity affect the spread of disease. Interplot interference is generally higher with smaller plots (Zhang et al. 1994; de Oliveira et al. 2005), potentially making the results from field trials less representative of largescale farming situations. In a field trial study of leaf rust resistance in barley varieties, Parlevliet and van Ommeren (1984) found the resistance of susceptible varieties to be generally overestimated and the resistance of partially resistant varieties to be greatly underestimated. Also, multiple field trial studies of wheat have demonstrated that interplot interference may possibly reduce the overall infestation levels of leaf rust (Bowen et al. 1984; Broers 1995) and mildew (Lipps and Madden 1992). In most of the current trials, mixtures have constituted only a minor proportion of the plots, and the chosen standard plot sizes at the experimental stations may not have been optimal for disease control.

Interplot interference from competition between neighbouring plots are found to introduce a similar type of error. Hence, in field trials of cereal varieties of different height, interplot interference can result in shorter varieties being depressed due to shading from taller neighbours, while the yields of taller varieties are increased (e.g. Kempton 1982, Kempton and Lockwood 1984). Interplot interference is found to be higher in trial environments of higher fertility (e.g. Aastveit et al. 1989; Clarke et al. 1998). Varying levels of interference across environments may thereby decrease the ability to detect any overall relationship in multi-environment trials such as that presented. The performance of nearest neighbour plots has previously been modelled in order to mitigate or eliminate the effects of interference (e.g. Kempton and Howes 1981; Kempton 1985; Talbot et al. 1995; Durban et al. 2001). However, this may sometimes introduce larger bias than that of the interference itself (Ainsley et al. 1995) and such models were therefore not applied.

Yield and stability analysis

Considering mixing effect on grain yield as the joint result of many types of inter-varietal and genotypeenvironments interaction, the results discussed above suggest that each type had only a minor influence. In trials such as these, where mixtures were not designed to study specific types of inter-varietal interaction, it may be more fruitful to consider general genotypic 
responses such as adaptability and resilience across the range of environmental conditions. These stability concepts are frequently used to compare crop properties (for a review, see Piepho 1998), including comparisons of variety mixtures and their components (e.g. Smithson and Lenné 1996; Juskiw et al. 2001; Cowger and Weisz 2008). Here, the overall yield variation, of mixtures was slightly higher than that of pure stand varieties, and since this measure encompasses both the response to environmental productivity and sensitivity to weeds and diseases, it seems more informative to consider these sources of variation separately.

Comparisons of genotypic responsiveness to environmental productivity are commonly obtained through the use of regression coefficients, $b_{i}$ (i.e. adaptability; Yates and Cochran 1938; Finlay and Wilkinson 1963; Eberhart and Russell 1966; Nurminiemi et al. 1996). In order to promote genotype comparisons across different studies, values of $b_{i}$ should always be interpreted in conjunction with the overall yield level of the genotype (Piepho 1998). In essence, genotypes with $b_{i}>1$ are responsive to high environmental productivity when having a high yield level (Clay and Allard 1969; Juskiw et al. 2001), such as Landora and Mix1. Oppositely, in conjunction with a low yield level it is indicative of high vulnerability to low environmental productivity, of which none were found in this study (Fig. 4). We found that $b_{i}$ values were sometimes higher than that of all their components (Mix3 and Mix4), whereas Juskiw et al. (2001) by a comparable approach found $b_{i}$ values of mixtures to be intermediate relative to component values. In the review of 36 studies, Smithson and Lenné (1996) found the environmental regression coefficients of both mixtures and component varieties to be very variable between studies. It is important to keep in mind that $b_{i}$ depends directly on the considered set of genotypes and environments. Absolute values of $b_{i}$ are therefore interpretable mainly within the considered data set, as has been shown for Nordic barley varieties (Nurminiemi and Rognli 1996), but ratios of $b_{i}$ of mixtures to component averages may be used for comparison between similar studies.

Variety mixtures are generally seen to deviate less from the environmental regression line than their component varieties (Smithson and Lenné 1996). This was confirmed here, using $s\left(d_{i}\right)^{2}$ as an overall indicator of sensitivity. All mixtures except Mix 4 were more resilient than two or all of their component varieties
(Table 4), Mix4 being among the least resilient of all mixtures and component varieties. Compared to the other mixtures, the component varieties of Mix4 were expected (from a priori characteristics) to differ the most in straw length and weed suppressiveness (Table 2), yet it remains unsolved as to how this may have contributed the observed sensitivity of Mix4.

Interaction between component varieties

The identified differences in stability of mixtures can be attributed to different levels of complementarity and compensation among component varieties. Since yields of single component varieties within mixture plots were unavailable, this interpretation can only be tentative.

Component variation in the environmental regression coefficient, $b_{i}$, may be an important indicator of the ability of component varieties to compensate for lower yields of other varieties in the mixture. Since compensation can occur at high as well as low levels of environmental productivity, varieties of lower responsiveness will be able to compensate for more responsive genotypes in less-productive environments and vice versa. It seems that the potential for compensation among mixture components is larger the more the components differ in response to environmental productivity measured by $b_{i}$. A simple regression of six data points (one for each mixture) supported this hypothesis, showing that the average mixing effect across environments increased significantly with the standard deviation of $b_{i}$ among component varieties $(r=0.64)$. In Mix 1, the component variety Orthega, ( $b_{i}$ close to the average of component varieties), was seen to have compensated the variety Landora (highest $b_{i}$ of any genotypic entity) at lower environmental productivity, whereas the opposite was seen at higher environmental productivity (Fig. 3a). The lowest $b_{i}$ of any genotypic entity was seen in the variety Fabel, which was bred for cultivation under low-input organic conditions. Fabel was component of Mix6, the $b_{i}$ of which was also lower than 1 and markedly lower than those of the remaining mixtures. This was not because the other component varieties could not compensate fully for the generally low yield of Fabel, but rather, it was a result of higher compensation in less productive environments (Fig. 3f). In the perspective that varieties can thus differ (and compensation occur) at all levels of productivity, the previously 
stated hypothesis that mixing effect will be higher when a compensating component variety has a steeper response to environmental productivity (e.g. Stützel and Aufhammer 1990) may seem over-simplistic.

Compensation will tend to be lower in mixtures whose component varieties provide more similar grain yields, i.e. when $\mathrm{D}(\hat{\mu})$ is smaller. This was observed in Mix 5 and Mix6, where Fabel provided lower yields in most trials compared to the other components. Additionally, one of the components of Mix5 (Harriot) generally yielded more than the other components throughout the range of productivity. The overall relative mixing effect of this mixture was thus probably due to compensation by Harriot through uptake of the resources not utilized by Fabel and Sebastian. Positive effects of inter-varietal complementarity, will thus tend to be more important for overall mixing effect with smaller $\mathrm{D}(\hat{\mu})$. In this case, mixture yields above the level of the highest yielding component $\left(\operatorname{MEmax}_{m l}>0\right)$ would clearly indicate an effect of complementarity. Substantially more examples of outyielding were seen at lower $\mathrm{D}(\hat{\mu})$ (Fig. 2b) and a significantly negative relationship between $\operatorname{MEmax}_{m l}$ and $\mathrm{D}(\hat{\mu})$ was confirmed, indicating that complementarity among mixture components is more important for mixing effect the less they differ in grain yield. Another support of this hypothesis was found in the mixture with the highest average mixing effect (Mix1). The component varieties of this mixture provided the lowest average $\mathrm{D}(\hat{\mu})$ (Fig. 1c) and the highest average mixing effect (Fig. 1a) of all mixtures and actually produced higher grain yields than its best yielding component in nearly half of the trials, most likely deriving from inter-varietal complementarity.

\section{Perspectives}

The indication that the potential for compensation among mixture components is higher the more they differ in yield level may seem trivial but nonetheless highlights the divergence of focus (on variety mixtures) between researchers and farmers. A large mixing effect (in relative as well as absolute terms) may easily be obtained by including one or more mixture components that perform substantially worse than the remaining components. This may provide the opportunity to study compensation and other mechanisms between genotypes in a mixture; however, it may not be of agronomical interest as it would most likely be accompanied by grain yield levels lower than what could be obtained using the best yielding variety. As an example, the requirement by farmers and authorities for a low level of disease susceptibility in all component varieties of marketed variety mixtures is contrasted by the fact that most published studies of fungal disease in variety mixtures involve one or more susceptible varieties (for reviews, see Smithson and Lenné 1996; Finckh et al. 2000).

The general experimental evidence of more stable yields of mixtures than the average of their pure stand component varieties may justify large-scale cultivation of variety mixtures in variable environments, such as organic farm systems. However, mixtures would be even more advantageous to farmers in general if, in addition, mixture yields were comparable to the highest yields of component varieties. Such mixtures exist, as exemplified by Mix 1 which was exceptionally good with respect to both yield level and stability. The component varieties of Mix 1 were all relatively highyielding. Noteworthy, a dynamic reference mixture composed of the three most high-yielding varieties from the previous year has been used at reference standard in Danish VCU testing for a number of years as it provides not only more stable but often also higher yields than any pure stand variety (pers. comm., M. Haastrup).

In essence, the successful formation of variety mixtures depends on the ability to select optimal a priori combinations of variety characteristics. The reported study suggests that, for a number of possible reasons, mixing effect may be difficult to predict from inter-varietal diversity with respect to single quantitative characteristics, even in the rare cases when a priori information on environmental conditions such as disease and weed loads is available. Proposed methods for predicting the best variety combinations based on thorough field trials, e.g. considering disease resistance (Mundt et al. 1995; Newton et al. 2008) or general mixing ability (Valentine 1982; Gallandt et al. 2001), may not always be feasible for practical farming. Prominently, new varieties often enter and leave the market within a short time-scale so that seeds of the varieties tested in such trials may be unavailable when recommendations based on those trials are eventually finished. Our findings suggest that deliberate combination of more general variety characteristics such as high yield levels and different environmental responsiveness is more attractive from an agronomic 
perspective, conferring a high potential for interaction between component varieties and their environment. If variety mixtures are to be adopted more widely by farmers, future research should address such mixtures more deliberately.

Acknowledgments Data were obtained from the BAR-OF project (DARCOF II, 2000-2005), funded by the International Centre for Research in Organic Food Systems (ICROFS, Denmark). We would like to thank Kristian Kristensen, Maria Finckh and two anonymous reviewers for useful comments on earlier drafts of the manuscript.

\section{References}

Aastveit AH, Buraas T, Gullord M (1989) Interplot competition in oats and barley variety trials. Acta Agric Scand 39(2): 159-168

Ainsley AE, Dyke GV, Jenkyn JF (1995) Inter-plot interference and nearest-neighbour analysis of field experiments. J Agric Sci Camb 125:1-9

Allard RW, Bradshaw AD (1964) Implications of genotype environment interactions. Crop Sci 4:503-508

Bowen KL, Teng PS, Roelfs AP (1984) Negative interplot interference in field experiments with leaf rust of wheat. Phytopath 74:1157-1161

Broers LHM (1995) Effect of interplot interference on the assessment of partial resistance to stem rust in durum wheat. Phytopath 85:233-237

Ceccarelli S (1996) In: Cooper M, Hammers GL (eds) Plant Adaptation and Crop Improvement. CAB International, Wallingford U.K., Icrisat, Andra Pradesh, India, IRRI, Manila, Philipines. pp 467-486

Clarke FR, Baker RJ, DePauw RM (1998) Interplot interference distorts yield estimates in spring wheat. Crop Sci 38:62-66

Clay RE, Allard RW (1969) A comparison of the performance of homogeneous and heterogeneous barley populations. Crop Sci 9:407-412

Cowger C, Weisz R (2008) Winter wheat blends (mixtures) produce a yield advantage in North Carolina. Agron J 100(1):169-177

de Oliveira SJR, Storck L, Lopes SJ, Lúcio AD, Feijó S, Damo HP (2005) Plot size and experimental unit relationship in exploratory experiments. Sci Agric 62(6):585-589

Durban M, Currie ID, Kempton RA (2001) Adjusting for fertility and competition in variety trials. J Agric Sci Camb 136:129-140

Eberhart SA, Russell WA (1966) Stability parameters for comparing varieties. Crop Sci 6:36-40

Finckh MR, Gacek ES, Goyeau H, Lannou C, Merz U, Mundt CC, Munk L, Nadziak J, Newton AC, Wolfe MS (2000) Cereal cultivar and species mixtures in practice, with emphasis on disease resistance. Agronomie 20:813-837

Finlay KW, Wilkinson GN (1963) The analysis of adaptation in a plant-breeding programme. Austr J Agric Res 14:742-754

Gallandt ER, Dofing SM, Reisenauer PE, Donaldson E (2001) Diallel analysis of cultivar mixtures in winter wheat. Crop Sci 41:792-796
Hansen PK, Kristensen K, Willas J (2008) A weed suppressive index for spring barley (Hordeum vulgare) varieties. Weed Res 48:225-236

Juskiw PE, Helm JH, Burnett PA (2001) Three-component barley mixtures: ratio effects in replacement series. Can J Plant Sci 81:651-656

Kaut AHEE, Mason HE, Navabi A, O'Donovan JT, Spaner D (2009) Performance and stability of performance of spring wheat variety mixtures in organic and conventional management systems in Western Canada. J AgricSci 147: 141-153

Kempton RA (1982) Adjustment for competition between varieties in plant breeding trials. J Agric Sci Camb 98: 599-611

Kempton RA (1985) Statistical models for interplot competition. Asp Appl Biol 10:110-120

Kempton RA, Howes CW (1981) The use of neighbouring plot values in the analysis of variety trials. Appl Stat 30:59-70

Kempton RA, Lockwood G (1984) Inter-plot competition in variety trials of field beans (Vicia faba L.). J Agric Sci Camb 103:293-302

Kiær LP, Skovgaard IM, Østergård H (2009) Grain yield increase in cereal variety mixtures: a meta-analysis of field trials. Field Crop Res 114:361-373

Langer I, Frey KJ, Bailey T (1979) Associations among productivity, production response and stability indexes in oat varieties. Euphytica 28:17-24

Lin CS, Binns MR, Lefkovitch LP (1986) Stability analysis: where do we stand? Crop Sci 26:894-900

Lipps PE, Madden LV (1992) Effects of plot size and border width on assessment of powdery mildew of winter wheat. Plant Dis 76(3):299-303

Lopez CG, Mundt CC (2000) Using mixing ability analysis from two-way cultivar mixtures to predict the performance of cultivars in complex mixtures. Field Crops Res 68: 121-132

Mundt CC, Brophy LS, Schmitt MS (1995) Choosing crop cultivars and cultivar mixtures under low versus high disease pressure: a case study with wheat. Crop Prot 14(6):509-515

Newton AC, Thomas WTB (1992) The effect of specific and non-specific resistance in mixtures of barley genotypes on infection by mildew (Erysiphe graminis f.sp. hordei) and on yield. Euphytica 59:73-81

Newton AC, Guy DC, Nadziak J, Gacek ES (2002) The effect of inoculum pressure, germplasm selection and environment on spring barley cultivar mixtures efficacy. Euphytica 125:325-335

Newton AC, Hackett CA, Swanston JS (2008) Analysing the contribution of component cultivars and cultivar combinations to malting quality, yield and disease in complex mixtures. J Sci Food Agric 88:2142-2152

Nurminiemi M, Rognli OA (1996) Regression analysis of yield stability is strongly affected by companion test varieties and locations: examples from a study of Nordic barley lines. Theor Appl Genet 93:468-476

Nurminiemi M, Bjørnstad A, Rognli OA (1996) Yield stability and adaptation of Nordic barleys. Euphytica 92:191-202

Østergård H, Jensen JW (2005) DARCOFenews, newsletter from Danish research centre for organic farming, September 2005. http://orgprints.org/8158/1/8158.pdf. Accessed 22 August 2011 
Østergård H, Kristensen K, Jensen JW (2005) In: Bueren ETL van, Goldringer I, Østergård, $\mathrm{H}$ (eds) Proceedings of the COST SUSVAR/ECO-PB Workshop on organic plant breeding strategies and the use of molecular markers, Driebergen, The Netherlands, 17-19 January, pp 28-30

Østergård $\mathrm{H}$, Kristensen $\mathrm{K}$, Pinnschmidt HO, Hansen PK, Hovmøller MS (2008) Predicting spring barley yield from variety-specific yield potential, disease resistance and straw length, and from environment-specific disease loads and weed pressure. Euphytica 163:391-408

Parlevliet JE, Van Ommeren A (1984) Interplot interference and the assessment of barley cultivars for partial resistance of leaf rust, Puccinia hordei. Euphytica 33:685-697

Patterson HD, Williams ER, Hunter EA (1978) Block designs for variety trials. J Agric Sci 90:395-400

Piepho H-P (1998) Methods for comparing the yield stability of cropping systems. J Agron Crop Sci 4:193-213

Robert N (2002) Comparison of stability statistics for yield and quality traits in bread wheat. Euphytica 128:333-341

Sage GCM (1971) Inter-varietal competition and its possible consequences for the production of $\mathrm{F} 1$ hybrid wheat. J Agric Sci 77:491-498

Smithson JB, Lenné JM (1996) Varietal mixtures: a viable strategy for sustainable productivity in subsistence agriculture. Ann Appl Biol 128:127-158
Stützel H, Aufhammer W (1990) The physiological causes of mixing effect in cultivar mixtures: a general hypothesis. Agr Syst 32:41-53

Talbot M, Milner AD, Nutkins MAE, Law JR (1995) Effect of interference between plots on yield performance in crop variety trials. J Agric Sci Camb 124:335-342

Valentine J (1982) Variation in monoculture and in mixture for grain yield and other characters in spring barley. Ann Appl Biol 101:127-141

Wilson JB (1988) Shoot competition and root competition. J Appl Ecol 25:279-296

Wolfe MS (2006) In: Østergård H, Fontaine L (eds) Proceedings of the COST SUSVAR workshop on cereal crop diversity: Implications for production and products, La Besse, France, 13-14 June, pp 8-40

Wolfe MS, Baresel JP, Desclaux D, Goldringer I, Hoad S, Kovacs G, Löschenberger F, Miedaner T, Østergård H, Lammerts van Bueren ET (2008) Developments in breeding cereals for organic agriculture. Euphytica 163:323-346

Yates F, Cochran WG (1938) The analysis of groups of experiments. J Agric Sci 28:556-580

Zhang R, Warrick AW, Myers DE (1994) Heterogeneity, plot shape effect and optimum plot size. Geoderma 62:183-197 